This is a pre-print draft. Please do not quote without contacting Ryan Burns first. Ryan.Burns1@ucalgary.ca

\title{
Synergizing Geoweb and Digital Humanitarian Research
}

\section{Introduction}

Humanitarian work is increasingly incorporating diverse sources of information and labor, in a shift that has significant repercussions on social, political, and economic relations. Exemplified by websites and communities such as Ushahidi, the Humanitarian OpenStreetMap Team, and the Standby Task Force, this development, commonly called "digital humanitarianism," sits at the juncture of new socio-technical practices, new epistemologies, and new institutional relationships (Burns 2014b; Crawford and Finn 2014). Digital humanitarianism involves formal humanitarian organizations tasking a large, unrestricted number of laypeople, often volunteers, with work related to gathering, producing, processing, publicizing, and mapping humanitarian data. For example, the Standby Task Force community members and Ushahidi users might be involved in collecting public information from social media and journalism sources, translating and processing that information, and visualizing it in a cartographic product ${ }^{i}$, to be used by formal responding agencies. The Humanitarian OpenStreetMap Team normally produces spatial data in crisis-affected areas by tracing new vector-based data over remotely-sensed images of crisis areas, in the OpenStreetMap platform. These data can include, then, infrastructure, expressions of need, or reports of security threats. Digital humanitarians contribute to the production, processing, and visualization of spatial data based on the assumption that such kinds of data, in their platforms, are needed by formal responders to more effectively deliver aid, and that volunteers - usually scattered across the globe - are able to deliver such data. Recent research on digital humanitarianism has focused on understanding and processing social media and mobile phone records as additional sources of data (Meier 2013b; UN OCHA 2013; Taylor and Schroeder 2014). Thus, digital humanitarianism encapsulates elements of the geoweb (Scharl and Tochtermann 2007; Leszczynski and Wilson 2013), crowdsourcing (Howe 2006), crisis mapping (Ziemke 2012), Big Data (Mayer-

Schönberger and Cukier 2013), and mass collaboration (Olafsson 2012).

Both digital humanitarian researchers and practitioners are increasingly foregrounding Big Data in their work, yet through narrow analytic lenses. These nascent conversations are often technical in nature, for instance in determining a quantitative measure of social media data's reliability. At other times they grapple with the policy potentials and hindrances associated with integrating Big Data into formal humanitarian and emergency management workflows. Researchers and practitioners are actively involved in advancing and advocating for these technologies. With this applied focus under way, recent research has begun theorizing Big Data digital humanitarianism as a set of socio-technical practices and relations, seeking synergies with critical data and technology studies (Crawford and Finn 2014; Dalton and Thatcher 2014; Sandvik et al. 2014). 
This is a pre-print draft. Please do not quote without contacting Ryan Burns first. Ryan.Burns1@ucalgary.ca

Digital humanitarianism uses spatial technologies to establish relations between geographically distant populations. Despite this inherent spatiality, to date geographers have researched little about the field. In this chapter, I explore ways geographers interested in Big Data can engage the field of digital humanitarianism to build empirical and theoretical connections with geoweb research. My primary goal is to draw on theoretical frameworks within geoweb research in order to highlight resonances with digital humanitarianism. I illuminate connections between existing Big Data, digital humanitarianism, and geoweb research, but am primarily concerned with new pressing questions and key linkages with existing research. Research on spatial technologies' social and political transformations provides the most compelling tools for conceiving of digital humanitarianism as a set of socio-technical practices and political-economic relations.

I begin by reviewing current research on digital humanitarianism. While more research is taking place outside geography's disciplinary boundaries, geographers are uniquely wellpositioned to theorize the social, political, and economic impacts of digital humanitarianism. I then detail three connections between digital humanitarianism and geoweb research: digital humanitarianism's spatialities, political economy, and knowledge politics. I conclude by drawing out larger implications of these connections.

\section{Current Research on Big Data Digital Humanitarianism}

Extant research on digital humanitarianism is predominantly descriptive and technical in nature. Conversations have revolved around determining data accuracy and credibility (Goodchild and Glennon 2010; Haworth and Bruce 2015; Li and Goodchild 2010), changing operational roles of emergency managers (Hughes and Palen 2012; Starbird and Palen 2013), developing solutions to technical problems, and streamlining its integration into policy and operations (Al-Akkad and Raffelsberger 2014; Hiltz, Kushma, and Plotnick 2014; van Gorp 2014). An oft-given explanation for the non-adoption of such technologies by the formal humanitarian sector is a lack of confidence in the reliability and actionability of digital humanitarian data (Burns and Shanley 2013; Hiltz, Kushma, and Plotnick 2014; Shanley et al. 2013). That is, the formal humanitarian sector often sees digital humanitarian data as either low in quality or of a nature that cannot inform established workflows and practices. Big Data factors prominently into these discussions as constitutive of new data sources and forms, with varying levels of accuracy (Meier 2012a, 2012b). To these ends, current research seeks to improve the data's accuracy, or to assign numerical values representing the given accuracy of the data (Gupta and Kumaraguru 2012; Vieweg 2012; Castillo, Mendoza, and Poblete 2013). In many cases, research explicitly seeks to control false or misleading social media data (Cohen 2013).

The emergence of Big Data has instigated new roles and responsibilities for formal humanitarian actors (Crowley and Chan 2011; Burns 2014b). In particular, the role of emergency managers is shifting to include monitoring and utilizing social media in crises (Palen, Vieweg, and Anderson 2011; Hughes and Palen 2012). As increasing numbers of laypeople contribute to crowdsourced data production (either wittingly or without informed consent (Harvey 2013; 
This is a pre-print draft. Please do not quote without contacting Ryan Burns first. Ryan.Burns1@ucalgary.ca

Schroeder 2014)), emergency and humanitarian managers are working to incorporate larger and more diverse data sources, displacing the formal sector from the primary producers of data (Liu et al. 2009; Starbird and Palen 2013).

Digital humanitarian operations face technological obstacles due to changing social and geographic contexts of implementation, evolving socio-technical practices, and emergent software platforms. As digital humanitarian technologies are mobilized in diverse places around the world, they require unique approaches and understandings of technology use (Acar and Muraki 2011; Chapman 2012; Verity 2011). This means adapting tools to local contexts in order to foster wide adoption and efficacious uses (Corbett and Keller 2006). While some research has focused on digital humanitarian interventions in political conflict zones (Bott, Gigler, and Young 2012; Stottlemyre and Stottlemyre 2012), digital humanitarian research is largely a-spatial, with "solutions" to problems framed as universal rather than geographically-contingent.

The narrow digital humanitarian research focus on technical descriptions can be partly explained by recent technological advances and the resulting shifted social uses of technologies. Digital humanitarians are developing new technologies to cope with Big Data, including evolving security threats (Chamales and Baker 2011; Chamales 2013; Goolsby 2013), unmanned aerial vehicles (UAVs; including the class of UAVs commonly called "drones") (Meier 2014; Sandvik and Lohne 2014), and automating work currently undertaken by contributors (Burns and Shanley 2013).

Formal-sector adoption of Big Data digital humanitarian technologies has been uneven in two senses. First, some institutions advocate for their adoption far more than others, with early adopters including the United Nations Office for the Coordination of Humanitarian Affairs (UN OCHA) (Capelo, Chang, and Verity 2012; Waldman, Verity, and Roberts 2013), the United States Federal Emergency Management Agency (FEMA), and the American Red Cross taking prominent roles (Virtual Social Media Working Group and DHS First Responders Group 2013). Agencies tend to adopt technologies directly related to their existing workflows and practices, rather than seeking to shift their practices and workflows, a tendency that tempers adoption (Burns 2014b). Another common reason given for a lack of widespread adoption is that existing policies and workflows hinder the changes required to efficiently utilize digital humanitarian technologies; in many cases emergency managers perceive policy hurdles to be insurmountable (Burns and Shanley 2013; Shanley 2012; Su, Wardell, and Thorkildsen 2013; WoodrowWilsonCenter 2012a). Some researchers have conducted analyses and provided recommendations regarding how to navigate legal and policy issues of Big Data digital humanitarian technologies (Robson 2012; Reidenberg et al. 2013; Young et al. 2013).

\section{Geographic research}

Despite the spatial nature of humanitarianism and the rich body of geographic literature critiquing it, geographers have, to-date, not contributed much to a theorization of digital humanitarianism. Early research has sought to position digital humanitarian technologies and 
This is a pre-print draft. Please do not quote without contacting Ryan Burns first. Ryan.Burns1@ucalgary.ca

practices alongside the geoweb. For instance, Goodchild and Glennon (2010) draw lines of resonance between social media, crisis mapping, and volunteered geographic information (VGI), suggesting that data produced in digital humanitarian technologies must undergo veracity tests similar to traditional data. Goodchild and Glennon are concerned primarily with this question of the accuracy of VGI, with accuracy being conceptualized as a measure of difference between an observed phenomenon's location on the earth and the location of its representation in geographic software; that is, a conceptualization reflecting much of digital humanitarian research outside disciplinary geography, Goodchild and Glennon implicitly posit that VGI is comprised of observable, material phenomena having a Cartesian (latitudinal and longitudinal) positionality, and accuracy is the measure of difference between this position and its representation. This is at odds with other potential understandings of knowledge representations, for instance the notion that knowledges can be interpersonal, emotional, performative, tactical, and associated with individual and collective memory - in a word, non-Cartestian (Elwood and Mitchell 2013; Kinsley 2013, 2014; Lin 2013). Additionally, while digital humanitarianism introduces new Big Data information flows to emergency management, these data are couched within relations, behaviors, and norms (Bowker 2005; boyd and Crawford 2012; Dalton and Thatcher 2014), all of which impact the data and the practices of data producers and emergency managers. In other words, a limited conception of Big Data digital humanitarianism would treat it as merely data.

Some researchers claim that Big Data, regardless of its accuracy, influences emergency managers' operations and decision-making practices. According to these views, mapping activities collect knowledge of where emergencies are occurring and presumably where aid and support should thus be distributed (Zook et al. 2010). For instance, Roche et al (2011) describe the ways new information flow structures embedded in the geoweb have begun shaping emergency management practices, arguing that the geoweb entails "key tools for crisis management and communication by all stakeholders: local authorities, emergency respondents, NGOs and the general public" $(2011,37)$. For Roche et al, digital humanitarian technologies primarily contribute new information sources and communication channels, which potentially shape the ways in which the emergency management sector responds to crises. Related research into formal-sector integration of digital humanitarian technologies has made similar claims, tacitly accepting that the presence of digital humanitarian technologies means the formal sector is indeed engaging them in some way (see: Liu and Palen 2010; Liu, Fraustino, and Jin 2015; Meier 2015).

Recently, some have begun proposing theoretical frameworks to understand the social and political implications of digital humanitarianism. Burns (2014b) has argued that the digital humanitarian case suggests Big Data should be conceptualized as a new set of practices, epistemologies, and socio-political relations. This stands in contrast with much extant research on Big Data in digital humanitarianism, which often in its framings disproportionately characterizes the integration as democratizing, empowering, and efficient. Instead, this approach highlights the modalities, variegations, and spatial situatedness of Big Data digital humanitarianism. Further, it indicates many potential further linkages with critical geographic 
This is a pre-print draft. Please do not quote without contacting Ryan Burns first. Ryan.Burns1@ucalgary.ca

theory, in particular from critical, participatory, and feminist GIS. Bittner et al (2013) suggest combining Actor-Network-Theory with a critical attention to hegemonic power relations to analyze the social nature of digital humanitarian technologies. Importantly, they argue that the politics of digital humanitarian technology reside not just in the visual representation of data, but also into software code, the positionality of digital humanitarians themselves, and the technological artifacts produced, such as platforms and application program interfaces (APIs). This point is likewise taken up by Burns (2014a), who demonstrates ways in which knowledge is politicized, contested, and represented through "moments of closure" in digital humanitarianism. Borrowing from feminist theories of technology, Burns argues that digital humanitarian technologies embody social and political relations that become temporarily solidified in technological artifacts.

The rest of this chapter develops these linkages. In the section that follows, I draw on the research discussed above to suggest ways the empirical phenomenon of Big Data digital humanitarianism may contribute to broad areas of interest to geoweb research. I show that geoweb research can be enriched and challenged by the particular case of digital humanitarianism, and geoweb scholars could use this case to refine theories of the geoweb. Within literature on the geoweb, I focus primarily on research into its social, political, and economic implications, as this area is imperative for the context of the humanitarian enterprise.

\section{Digital Humanitarianism and the Geoweb}

In this section I develop four linkages between Big Data digital humanitarianism and geoweb research. Above, I argued that scholars have not yet fully elucidated the ways these topics manifest in digital humanitarianism, yet I posit that exploring these topics would extend and help refine theorizations of the geoweb. Implicit to this argument is the assumption that geographers are uniquely well-positioned to build a theorization of digital humanitarianism ${ }^{\mathrm{ii}}$. Specifically, I discuss digital humanitarianism's spatialities, political economy, and knowledge politics.

\section{The spatialities of Big Data digital humanitarianism}

Much like humanitarianism writ large, digital humanitarianism involves (re)producing spatial relationships between those who need help and those who deliver it (Fassin 2012). It is particularly imperative to examine digital humanitarianism in this regard, since the spatial relationship is extended to include those contributing from afar. Collaborators on humanitarian projects no longer need be near the site of the crisis or in the management offices and headquarters; instead, individuals may produce, process, and represent data while being located anywhere with an internet connection. This is accomplished through the mobilization of spaces specific to digital humanitarianism, including its software platforms, lines of code, data models, and data representations. These are distinctive material spaces, both in the sense that their lines of code impact absolute geographies through the distribution of aid and resources; and in the sense that they cannot function independent of the fiberoptic cables, servers, and real bodies that drive them (Kitchin and Dodge 2012; Kinsley 2014). 
This is a pre-print draft. Please do not quote without contacting Ryan Burns first. Ryan.Burns1@ucalgary.ca

The potential for dispersed digital humanitarianism, however, raises empirical questions regarding who actually contributes to these efforts. If Big Data digital humanitarianism reflects the unevenness of data production observable in other user-generated information efforts such as Wikipedia (Graham, Hale, and Stephens 2011; Graham et al. 2014), more research will be needed to address the implications of this unevenness. At least one prominent digital humanitarian tool, Ushahidi, originated in the global South (Okolloh 2009), but its origin says little about current usage, and to date research has not examined the geographic origin of current digital humanitarian contributors. This could be of particular concern if, for instance, remote contributors have little understanding of the roots of the crisis at hand, have little stake in the "success" of the intervention, or have reflected sparsely on how their labor contributes.

Regardless of how geographically dispersed digital humanitarians are, several theoretical questions emerge regarding these spatialities._First, what can be known by those who are remote from the site of the intervention, and what does that mean for the types of needs and knowledges that are mapped? In humanitarian crises there must be a relation between distance and the knowledge that one can have of that crisis. This question seeks the epistemic limit of Big Data digital humanitarianism. Second, what conceptual shifts regarding humanitarianism occur when geographically_dispersed laypeople - those with no expert knowledge of how humanitarianism operates - contribute to humanitarian interventions? This may be especially pertinent when Big Data digital humanitarian projects occur outside sanctioned contexts, as was the case with Mission 4636 in the 2010 Haiti earthquake response, and in ongoing CrowdMap platforms established in the wake of disasters and crises around the globe. Third, what kinds of assumptions about who has resources and who is able to deliver them motivate digital humanitarian activities? In other words, what must individuals assume about their spatial relationship to those they help, prior to contributing to digital humanitarianism?

These questions resonate with emerging geoweb research exploring the unevenness of user-generated data production. Geoweb research has shown that Big Data is produced by - and about - the global North (Haklay 2013; Graham et al. 2014); such data usually reflects and reproduces extant gender relations (Stephens 2013; Leszczynski and Elwood 2014); and influences geographies of consumption (Graham 2010; Thatcher 2013). Exploring the spatialities of digital humanitarianism answers Crampton et al's (2013) call to explore spatialities "beyond the proximate" to understand how humanitarian Big Data production occurs across diverse spatial scales and relational distances.

\section{The political economy of Big Data digital humanitarianism}

Big Data digital humanitarianism is emerging alongside significant political-economic shifts that remain to be explored. These shifts are largely the result and harbingers of two parallel processes. First, Big Data digital humanitarianism is often offered as the innovation that can allow the formal humanitarian sector to operate in the context of increased pressures to work more efficiently and effectively (Kirkpatrick 2011; Letouzé 2012a, 2012b; UN OCHA 2013). Big Data has become prominent within humanitarianism because proponents suggest it will allow humanitarians to fulfill this need, and Big Data has thus emerged here as the result of political- 
This is a pre-print draft. Please do not quote without contacting Ryan Burns first. Ryan.Burns1@ucalgary.ca

economic processes within humanitarianism. Second, the private sector has come to play a prominent role in Big Data digital humanitarianism, as they develop many of the technologies needed to produce and effectively leverage Big Data (Burns and Shanley 2013). Examples of private companies involved in such Big Data processes include Twitter and Instagram through alert systems, Google's Crisis Response Team in its development of crisis mapping platforms, and Esri in developing emergency management software incorporating digital humanitarian data. Eric Rasmussen, a prominent actant in the digital humanitarian community and CEO of the private business Infinitum Humanitarian Systems, said at a recent digital humanitarian workshop, "....in these discussions, please let the private sector take care of this. We will address this problem for you, we will take the research, we will commercialize it, and we'll sell it back to you for cheap" (WoodrowWilsonCenter 2012b) ${ }^{\mathrm{iii}}$.

These political-economic processes often go hand-in-hand with a reconceptualization of data vis-à-vis Big Data. One of the clearest examples comes from Robert Kirkpatrick, director of the UN's Global Pulse program seeking to harvest Big Data for development and humanitarianism._Kirkpatrick (2011) has offered a new conceptualization of Big Data as aid. According to this conceptualization, data does not merely capture information about a crisis, but it also carries material value. In this sense, needs of humanitarian crisis victims can be met when humanitarian actors circulate Big Data quickly and efficiently enough (Decker 2013; Meier 2013a). Through this reconceptualization, Big Data becomes a circulating unit of value similar to other commodities, one which can and should be delivered in zones of humanitarian crisis. This therefore constitutes a new locus of political-economic relations and processes that bears critical exploration.

Geoweb scholars have recently begun elucidating the political-economic relations in which the geoweb should be situated. In particular, Leszczynski (2012) has argued that the geoweb should be understood as signaling both the roll-back of the state from mapping roles and responsibilities formerly within its purview; and as the roll-out of the state in the form of new regulations, frameworks, and markets for the private sector. According to Leszczynski, the geoweb has been made possible by the state handing over its duties to individuals and private sector companies. Much remains to be explored in this area of geoweb research, and Big Data digital humanitarianism provides a unique case due to its potentially stark consequences. For example, while Internet researchers have theorized digital labor in relation to generating surplus value (Fuchs and Sevignani 2013), questions remain regarding the reasons private companies are funding many digital humanitarian activities while simultaneously relying on volunteered labor. For what purposes is the private sector entering humanitarianism via digital humanitarianism? What impacts do remote volunteer projects have on local community economies, where in many cases local people are in need of paid work? The case of Big Data digital humanitarianism raises several questions that could contribute to geoweb scholars' efforts to understand the political economy of the geoweb.

\section{The knowledge politics of Big Data digital humanitarianism}


This is a pre-print draft. Please do not quote without contacting Ryan Burns first. Ryan.Burns1@ucalgary.ca

As in the social sciences more broadly, within digital humanitarianism Big Data signals new forms of contestation around knowledge legitimacy, and differing amounts of weight given to various kinds of claims (Elwood and Leszczynski 2013). In digital humanitarianism these "knowledge politics" take the form of deliberations over what kinds of knowledges to include, how to include them, and the terms on which they should be included (Burns 2014a). These knowledge politics in digital humanitarianism have implications for how the technologies are engaged by the formal sector, and therefore, how shifts in aid distribution are to take place. In other words, the ways in which digital humanitarian technologies collect, process, and represent Big Data has implications for how material needs are met (Burns 2014b).

Much of Big Data digital humanitarian research has assumed Big Data contains a degree of representativeness, even if it is simply representative of the small sample of the population who produces social media data (Letouzé 2012a; Meier 2013b; UN OCHA 2013). M ost humanitarian agencies recognize that the knowledges represented in Big Data are not representative of the population at large (Meier 2012a), yet they see data to be representative of the population that produces it. This runs in contrast with recent scholarship showing the performative nature of knowledge produced through social media; much recent work has argued that social media data is produced as a way of demonstrating a desirable persona of oneself (Kinsley 2013; Lin 2013). Big Data within digital humanitarianism could thus be seen not as an objective and situated recording of a reality, but rather a mediated presentation of the image one wants others to know about them. The difference here is between seeing Big Data as a source of information to guide the dispersal of resources on the one hand, and as a murky lens through which to view a limited number of perspectives of a crisis.

Research into the knowledge politics of the geoweb has shown this to be a fruitful area. While such research has shed light onto the uneven representation and contribution of knowledges encoded by data, less is known about the particular ways in which this has factored into knowledge of the world. Current geoweb research is addressing this question, and digital humanitarianism is an imperative case to consider, as it mobilizes relations that rely explicitly on knowledge of other places. In humanitarian contexts, it may be empowering and assist in recovery and future mitigation efforts for representational technologies to incorporate local knowledges and ways of knowing, rather than to have a structure of knowledge (e.g., prefabricated databases, Cartesian representations) foisted upon local communities. Big Data in the form of social media may contribute to this goal, insofar as it allows a degree of flexibility of expression not seen in previous data forms. In this way digital humanitarianism presents unique challenges and ethical questions to knowledge politics in geoweb research. Specific questions that remain include: who can - and who does - represent places in digital humanitarian contexts, and what kinds of marginalizations arise because of these asymmetries? How is knowledge about individual crises, as well as crisis writ large, shaped by digital humanitarian technologies? What kinds of struggles are undertaken by "victims" of humanitarian crises in order to make their knowledges visible - or in some cases to keep their knowledges invisible (Burns 2014a; Young and Gilmore 2014)? 
This is a pre-print draft. Please do not quote without contacting Ryan Burns first. Ryan.Burns1@ucalgary.ca

\section{Conclusion}

In this chapter I have argued that geographers studying the geoweb have not sufficiently considered the case of digital humanitarianism, and that to do so would lend unique and productive insights. I have reflected on potential contributions, focusing on the social and political implications of digital humanitarianism. I look specifically at current theorizations of the geoweb's spatialities, political economy, and knowledge politics, drawing lines of productive resonance with digital humanitarianism.

Further research is needed at the juncture of the geoweb and digital humanitarianism to expand geographers' understanding of the shifting socio-technical practices observed in the world today. Such research would contribute deeper understanding of digital humanitarianism, but would also nuance current conceptualizations of the geoweb. As an umbrella term for shifting data and socio-technical phenomena, the "geoweb" currently does not adequately account for the range of contexts in which new data and socio-technical practices occur. Digital humanitarianism enrolls unique institutional, social, and political-economic relations that are distinct from - and therefore stand to refine - what is typically considered the geoweb.

Additionally, greater understanding of digital humanitarianism is imperative due to the significant impact that humanitarianism has on current global social and political relations. The last several decades have witnessed the emergence of a general sense of cosmopolitan responsibility (Calhoun 2004; Roy 2010), with appeals to humanitarian and moral sentiments becoming the most likely to generate support for humanitarian intervention (Fassin 2012). "Humanitarian reason" is thus becoming an increasingly powerful force in the world (Calhoun 2004; Fassin 2012), and more research is needed to understand the impacts incurred by the incorporation of Big Data and digital humanitarian technologies (Crawford and Finn 2014). Geoweb scholars are well-positioned to address these questions.

\section{Full Bibliography}

Acar, A., and Y. Muraki. 2011. Twitter for crisis communication: lessons learned from Japan's tsunami disaster. International Journal of Web Based Communities 7 (3):392-402.

Al-Akkad, A., and C. Raffelsberger. 2014. How Do I Get This App? A Discourse on Distributing Mobile Applications Despite Disrupted Infrastructure. In Proceedings of the 11th International ISCRAM Conference, eds. S. R. Hiltz, M. S. Pfaff, L. Plotnick, and P. C. Shih, 565-569. University Park, PA.

Bittner, C., G. Glasze, and C. Turk. 2013. Tracing Contingencies: Analyzing the Political in Assemblages of Web 2.0 Cartographies. GeoJournal 78 (6):935-948.

Bott, M., B.-S. Gigler, and G. Young. 2012. The Role of Crowdsourcing for Better Governance in Fragile State Contexts. http://www.scribd.com/doc/80707030/The-Role-of- 
This is a pre-print draft. Please do not quote without contacting Ryan Burns first. Ryan.Burns1@ucalgary.ca

Crowdsourcing-for-Better-Governance-in-Fragile-State-Contexts (last accessed 15 May 2013).

Bowker, G. C. 2005. Memory Practices in the Sciences. Cambridge, MA: MIT Press.

boyd, danah, and K. Crawford. 2012. Critical Questions for Big Data: Provocations for a cultural, technological, and scholarly phenomenon. Information, Communication \& Society 15 (5):662-679.

Burns, R. 2014a. Moments of Closure in the Knowledge Politics of Digital Humanitarianism. Geoforum 53 (May):51-62.

- 2014b. Rethinking Big Data in Digital Humanitarianism: Practices, Epistemologies, and Social Relations. GeoJournal. http://www.springer.com/-

/0/ae7fdd425619448789b6e052edb650a3 (last accessed 13 October 2014).

Burns, R., and L. Shanley. 2013. Connecting Grassroots to Government for Disaster Management: Workshop Report. Washington, D.C.: Woodrow Wilson International Center for Scholars. http://www.scribd.com/doc/165813847/Connecting-Grassroots-toGovernment-for-Disaster-Management-Workshop-Summary (last accessed 24 September 2013).

Calhoun, C. 2004. A World of Emergencies: Fear, Intervention, and the Limits of Cosmopolitan Order. Canadian Review of Sociology \& Anthropology 41 (4):373-395.

Capelo, L., N. Chang, and A. Verity. 2012. Guidance for Collaborating with Volunteer \& Technical Communities. Digital Humanitarian Network. http://www.scribd.com/doc/101420316/Guidance-for-Collaborating-With-v-amp-TCs (last accessed 28 January 2013).

Castillo, C., M. Mendoza, and B. Poblete. 2013. Predicting Information Credibility in Timesensitive Social Media. Internet Research 23 (5):560-588.

Chamales, G. 2013. Towards Trustworthy Social Media and Crowdsourcing. Washington, DC: Woodrow Wilson International Center for Scholars. http://www.scribd.com/doc/138508756/Towards-Trustworthy-Social-Media-andCrowdsourcing (last accessed 20 May 2013).

Chamales, G., and R. Baker. 2011. Securing Crisis Maps in Conflict Zones. Seattle, WA http://roguegenius.com/wp-content/uploads/2011/11/Securing-Crisis-Maps-in-ConflictZones-Chamales_BakerIEEE-Formatted.pdf.

Chapman, K. 2012. Community Mapping for Exposure in Indonesia. http://hot.openstreetmap.org/updates/2012-0731_indonesian_project_report_get_it_while_its_hot. 
This is a pre-print draft. Please do not quote without contacting Ryan Burns first. Ryan.Burns1@ucalgary.ca

Cohen, S. E. 2013. Sandy Marked a Shift for Social Media Use in Disasters. Emergency Management. http://www.emergencymgmt.com/disaster/Sandy-Social-Media-Use-inDisasters.html\#.UTkc9hoaKdo.facebook (last accessed 9 March 2013).

Corbett, J., and P. Keller. 2006. Using Community Information Systems to Communicate Traditional Knowledge Embedded in the Landscape. Participatory Learning and Action $54: 21-27$.

Crampton, J., M. Graham, A. Poorthuis, T. Shelton, M. Stephens, M. Wilson, and M. Zook. 2013. Beyond the Geotag: Situating "Big Data" and Leveraging the Potential of the Geoweb. Cartography and Geographic Information Science 40 (2):130-139.

Crawford, K., and M. Finn. 2014. The Limits of Crisis Data: Analytical and Ethical Challenges of Using Social and Mobile Data to Understand Disasters. GeoJournal. http://link.springer.com/article/10.1007/s10708-014-9597-z (last accessed 12 March 2015).

Crowley, J., and J. Chan. 2011. Disaster relief 2.0: the future of information sharing in humanitarian emergencies. UN Foundation \& Vodafone Foundation Technology Partnership. http://www.globalproblems-globalsolutionsfiles.org/gpgs_files/pdf/2011/DisasterResponse.pdf.

Dalton, C., and J. Thatcher. 2014. What Does a Critical Data Studies Look Like, and Why Do We Care? Seven Points for a Critical Approach to "Big Data." Society and Space Open Site. http://societyandspace.com/material/commentaries/craig-dalton-and-jim-thatcherwhat-does-a-critical-data-studies-look-like-and-why-do-we-care-seven-points-for-acritical-approach-to-big-data/ (last accessed 5 August 2014).

Decker, K. 2013. Big Data for Humanitarian Assistance and Disaster Response.

Elwood, S., and A. Leszczynski. 2013. New Spatial Media, New Knowledge Politics. Transactions of the Institute of British Geographers 38 (4):544-559.

Elwood, S., and K. Mitchell. 2013. Another Politics Is Possible: Neogeographies, Visual Spatial Tactics, and Political Formation. Cartographica 48 (4):275-292.

Farmer, C. J., and A. Pozdnoukhov. 2012. Building Streaming GIScience from Context, Theory, and Intelligence. In Proceedings of the Workshop on GIScience in the Big Data Age. Columbus, $\mathrm{OH}$ http://ncg.nuim.ie/content/staff/staff/downloads/apozdnoukhov/GIScience2012.pdf (last accessed 26 May 3015).

Fassin, D. 2012. Humanitarian Reason: A Moral History of the Present. Berkeley, CA: University of California Press.

Fuchs, C., and S. Sevignani. 2013. What Is Digital Labour? What Is Digital Work? What's Their Difference? And Why Do These Questions Matter for Understanding Social Media? tripleC 11 (2):237-293. 
This is a pre-print draft. Please do not quote without contacting Ryan Burns first. Ryan.Burns1@ucalgary.ca

Goodchild, M., and J. A. Glennon. 2010. Crowdsourcing geographic Information for Disaster Response: A Research Frontier. International Journal of Digital Earth 3 (3):231-241.

Goolsby, R. 2013. On Cybersecurity, Crowdsourcing, and Social Cyber-Attack. Washington, DC: Woodrow Wilson International Center for Scholars. http://www.scribd.com/doc/127219170/On-Cybersecurity-Crowdsourcing-and-SocialCyber-Attack-Commons-Lab-Policy-Memo-Series-Vol-1 (last accessed 20 May 2013).

Van Gorp, A. 2014. Integration of Volunteer and Technical Communities into the Humanitarian Aid Sector: Barriers to Collaboration. In Proceedings of the 11th International ISCRAM Conference, 622-631. University Park, PA.

Graham, M. 2010. Neogeography and the Palimpsests of Place: Web 2.0 and the Construction of a Virtual Earth. Tijdschrift voor Economische en Sociale Geografie 101 (4):422-436.

Graham, M., S. Hale, and M. Stephens. 2011. Geographies of the World's Knowledge. London: Convoco!

Graham, M., B. Hogan, R. Straumann, and A. Medhat. 2014. Uneven Geographies of Usergenerated Information: Patterns of Increasing Informational Poverty. Annals of the Association of American Geographers 104 (4):746-764.

Gupta, A., and P. Kumaraguru. 2012. Credibility Ranking of Tweets during High Impact Events. In Privacy and Security in Online Social Media. Lyon, France: ACM http://precog.iiitd.edu.in/Publications_files/a2-gupta.pdf (last accessed 17 August 2014).

Haklay, M. 2013. Neogeography and the delusion of democratisation. Environment and Planning A 45 (1):55-69.

Harvey, F. 2013. To Volunteer or to Contribute Locational Information? Towards Truth in Labeling for Crowdsourced Geographic Information. In Crowdsourcing Geographic Knowledge, eds. D. Sui, S. Elwood, and M. Goodchild, 31-42. Amsterdam: Springer.

Haworth, B., and E. Bruce. 2015. A Review of Volunteered Geographic Information for Disaster Management. Geography Compass 9 (5):237-250.

Hiltz, S. R., J. Kushma, and L. Plotnick. 2014. Use of Social Media by U.S. Public Sector Emergency Managers: Barriers and Wish Lists. In Proceedings of the 11th International ISCRAM Conference, eds. S. R. Hiltz, M. S. Pfaff, L. Plotnick, and P. C. Shih, 602-611. University Park, PA http://iscram2014.ist.psu.edu/sites/default/files/misc/proceedings/p11.pdf (last accessed 10 May 2015).

Howe, J. 2006. The Rise of Crowdsourcing. Wired. http://www.wired.com/wired/archive/14.06/crowds_pr.html (last accessed 10 May 2013).

Hughes, A. L., and L. Palen. 2012. The Evolving Role of the Public Information Officer: An Examination of Social Media in Emergency Management. Journal of Homeland Security 
This is a pre-print draft. Please do not quote without contacting Ryan Burns first. Ryan.Burns1@ucalgary.ca

and Emergency Management 1976.

http://www.degruyter.com/view/j/jhsem.2012.9.issue-1/1547-7355.1976/1547-

7355.1976.xml.

Kinsley, S. 2013. Beyond the Screen: Methods for Investigating Geographies of Life "Online." Geography Compass 7 (8):540-555.

- 2014. The Matter of "Virtual" Geographies. Progress in Human Geography 38 (3):364384.

Kirkpatrick, R. 2011. Data Philanthropy: Public \& Private Sector Data Sharing for Global Resilience. UN Global Pulse. http://www.unglobalpulse.org/blog/data-philanthropypublic-private-sector-data-sharing-global-resilience (last accessed 20 February 2014).

Kitchin, R., and M. Dodge. 2012. Code/Space: Software and Everyday Life. Cambridge, MA: MIT Press.

Leszczynski, A. 2012. Situating the Geoweb in Political Economy. Progress in Human Geography 36 (1):72-89.

Leszczynski, A., and S. Elwood. 2014. Feminist Geographies of New Spatial Media. The Canadian Geographer.

Leszczynski, A., and M. Wilson. 2013. Guest Editorial: Theorizing the Geoweb. GeoJournal 78 (6):915-919.

Letouzé, E. 2012a. Big Data for Development: Challenges \& Opportunities. UN Global Pulse. http://www.unglobalpulse.org/projects/BigDataforDevelopment (last accessed 6 October 2014).

- 2012b. Can Big Data from Cellphones Help Prevent Conflict? Global Observatory. http://theglobalobservatory.org/analysis/380-can-big-data-from-cellphones-help-preventconflict.html (last accessed 5 March 2103).

Li, L., and M. Goodchild. 2010. The Role of Social Networks in Emergency Management: A Research Agenda. International Journal of Information Systems for Crisis Response and Management 2 (4):49-59.

Lin, W. 2013. Situating performative neogeography: tracing, mapping, and performing "Everyone's East Lake." Environment and Planning A 45 (1):37-54.

Liu, B., J. Fraustino, and Y. Jin. 2015. How Disaster Information Form, Source, Type, and Prior Disaster Exposure Affet Public Outcomes: Jumping on the Social Media Bandwagon? Journal of Applied Communication Research 43 (1):44-65.

Liu, S. B., and L. Palen. 2010. The New Cartographers: Crisis Map Mashups and the Emergence of Neogeographic Practice. Cartography and Geographic Information Science 37 (1):6990. 
This is a pre-print draft. Please do not quote without contacting Ryan Burns first. Ryan.Burns1@ucalgary.ca

Liu, S., L. Palen, J. Sutton, A. Hughes, and S. Vieweg. 2009. Citizen photojournalism during crisis events. Citizen Journalism: Global Perspectives. New York: Peter Lang :43-63.

Mayer-Schönberger, V., and K. Cukier. 2013. Big Data: A Revolution That Will Transform How We Live, Work, and Think. New York: Houghton Mifflin Harcourt Publishing Company.

Meier, P. 2012a. Debating the Value of Tweets For Disaster Response (Intelligently). iRevolution. http://irevolution.net/2012/12/17/debating-tweets-disaster/ (last accessed 19 June 2014).

- 2012b. What Was Novel About Social Media Use During Hurricane Sandy? iRevolution. http://irevolution.net/2012/10/31/hurricane-sandy/ (last accessed 8 December 2012).

_ 2013a. Human Computation for Disaster Response. In Handbook of Human Computation, ed. P. Michelucci, 95-104. Springer New York http://dx.doi.org/10.1007/978-1-4614-8806-4_11.

— 2013b. What Is Big (Crisis) Data? iRevolution. irevolution.net/2013/06/27/what-is-bigcrisis-data/ (last accessed 9 August 2014).

- 2014. Humanitarians in the Sky: Using UAVs for Disaster Response. iRevolution. http://irevolution.net/2014/06/25/humanitarians-in-the-sky-using-uavs-for-disasterresponse/ (last accessed 17 August 2014).

- 2015. Digital Humanitarians: How Big Data Is Changing the Face of Humanitarian Response. Boca Raton, FL: CRC Press.

Okolloh, O. 2009. Ushahidi, or "Testimony": Web 2.0 Tools for Crowdsourcing Crisis Information. Participatory Learning and Action 59 (1):65-70.

Olafsson, G. 2012. Humanitarian Response in the Age of Mass Collaboration and Networked Intelligence. Washington, D.C.: Woodrow Wilson International Center for Scholars. http://wilsoncenter.org/sites/default/files/VisionfortheFuture_PositionPaper_0.pdf (last accessed 8 February 2013).

Palen, L., S. Vieweg, and K. M. Anderson. 2011. Supporting "Everyday Analysts" in Safety- and Time-Critical Situations. The Information Society 27:52-62.

Reidenberg, J., R. Gellman, J. Debelak, A. Elewa, and N. Liu. 2013. Privacy and Missing Persons in Natural Disasters: Striking the Right Balance Between Rights and Needs. Washington, D.C.: Woodrow Wilson International Center for Scholars.

Robson, E. 2012. Responding to Liability: Evaluating and Reducing Tort Liability for Digital Volunteers. Washington, D.C.: Woodrow Wilson International Center for Scholars. http://www.wilsoncenter.org/sites/default/files/responding_to_liability_1.pdf (last accessed 6 April 2013). 
This is a pre-print draft. Please do not quote without contacting Ryan Burns first. Ryan.Burns1@ucalgary.ca

Roche, S., E. Propeck-Zimmermann, and B. Mericskay. 2011. GeoWeb and crisis management: issues and perspectives of volunteered geographic information. GeoJournal :1-20.

Roy, A. 2010. Poverty Capital. London: Taylor \& Francis Group.

Sandvik, K., M. Jumbert, J. Karlsrud, and M. Kaufmann. 2014. Humanitarian Technology: A Critical Research Agenda. International Review of the Red Cross. http://dx.doi.org/10.1017/S1816383114000344 (last accessed 29 March 2015).

Sandvik, K., and K. Lohne. 2014. The Rise of the Humanitarian Drone: Giving Content to an Emerging Concept. Millenium: Journal of International Studies :1-20.

Scharl, A., and K. Tochtermann. 2007. The Geospatial Web: How Geobrowsers, Social Software and the Web 2.0 Are Shaping the Network Society. London: Springer-Verlag.

Schroeder, R. 2014. Big Data and the Brave New World of Social Media Research. Big Data \& Society 1 (2). http://bds.sagepub.com/content/1/2/2053951714563194 (last accessed 10 May 2015).

Shanley, L. 2012. Opportunities and Challenges in Crisis Informatics.

Shanley, L., R. Burns, Z. Bastian, and E. Robson. 2013. Tweeting up a Storm: The Promise and Perils of Crisis Mapping. Photogrammetric Engineering \& Remove Sensing 79 (10):865879.

Starbird, K., and L. Palen. 2013. Working and Sustaining the Virtual "Disaster Desk." In Proceedings of the ACM 2013 conference on Computer Supported Cooperative Work. San Antonio, TX: ACM Press https://www.cs.colorado.edu/ palen/Home/Articles_by_Year_files/starbird-palencscw2013_final-2.pdf (last accessed 17 August 2014).

Stephens, M. 2013. Gender and the GeoWeb: Divisions in the Production of User-generated Cartographic Information. GeoJournal 78 (6):981-996.

Stottlemyre, S., and S. Stottlemyre. 2012. Crisis Mapping Intelligence Information During the Libyan Civil War: An Exploratory Case Study. Policy and Internet 4 (3-4):24-39.

Su, Y. S., C. Wardell, and Z. Thorkildsen. 2013. Social Media in the Emergency Management Field: 2012 Survey Results. CNA Analysis \& Solutions. http://www.cna.org/sites/default/files/research/SocialMedia_EmergencyManagement.pdf (last accessed 29 April 2015).

Taylor, L., and R. Schroeder. 2014. Is Bigger Better? The Emergence of Big Data as a Tool for International Development Policy. GeoJournal. http://link.springer.com/article/10.1007\%2Fs10708-014-9603-5 (last accessed 10 May 2015). 
This is a pre-print draft. Please do not quote without contacting Ryan Burns first. Ryan.Burns1@ucalgary.ca

Thatcher, J. 2013. Avoiding the Ghetto through Hope and Fear: An Analysis of Immanent Technology Using Ideal Types. GeoJournal 78 (6):967-980.

United Nations Office for the Coordination of Humanitarian Affairs. 2013. Humanitarianism in the Network Age. UN Office for the Coordination of Humanitarian Affairs. https://ochanet.unocha.org/p/Documents/WEB Humanitarianism in the Network Age vF single.pdf (last accessed 15 April 2013).

Verity, A. 2011. OCHA's Lessons Learned: Collaboration with V\&TCs for Libya and Japan. Geneva: United Nations Office for the Coordination of Humanitarian Affairs.

Vieweg, S. 2012. Situational Awareness in Mass Emergency: A Behavioral and Linguistic Analysis of Microblogged Communications. http://works.bepress.com/cgi/viewcontent.cgi?article=1029\&context=vieweg (last accessed 24 June 2014).

Virtual Social Media Working Group, and DHS First Responders Group. 2013. Lessons Learned: Social Media and Hurricane Sandy. US Department of Homeland Security. http://www.ghinternational.com/docs/DHS_VSMWG_Lessons_Learned_Social_Media_ and_Hurricane_Sandy_Formatted_June_2013_FINAL.pdf (last accessed 17 August 2014).

Waldman, A., A. Verity, and S. Roberts. 2013. Guidance for Collaborating with Formal Humanitarian Organizations. Geneva: Digital Humanitarian Network. https://app.box.com/s/w25sqotkg4qc2f2ch1ii (last accessed 7 February 2014).

WoodrowWilsonCenter. 2012a. Legal and Policy Issues. Washington, D.C.: Youtube. http://youtu.be/apEMNJFnBEM (last accessed 30 June 2013).

- 2012b. Research Challenges. Washington, D.C.: Youtube. http://youtu.be/uTIT3mkQhew (last accessed 12 March 2014).

Young, J., and M. Gilmore. 2014. Subaltern Empowerment in the Geoweb: Tensions between Publicity and Privacy. Antipode 46 (2):574-591.

Young, J., D. Wald, P. Earle, and L. Shanley. 2013. Transforming Earthquake Detection and Science Through Crowdsourcing. Washington, D.C.: Woodrow Wilson International Center for Scholars.

Ziemke, J. 2012. Crisis Mapping: The Construction of a New Interdisciplinary Field? Journal of Map \& Geography Libraries: Advances in Geospatial Information, Collections \& Archives 8 (2):101-117.

Zook, M., M. Graham, T. Shelton, and S. Gorman. 2010. Volunteered Geographic Information and Crowdsourcing Disaster Relief: A Case Study of the Haitian Earthquake. World Medical \& Health Policy 2 (2):7-33. 
This is a pre-print draft. Please do not quote without contacting Ryan Burns first. Ryan.Burns1@ucalgary.ca

${ }^{\mathrm{i}}$ This process was recently used in response to the 2015 earthquake in Nepal (see: http://blog.standbytaskforce.com/deployments/nepal-earthquake-2015/).

ii Farmer and Pozdnoukhov (2012) have argued similarly with regard to geography and Big Data.

iii To be sure, Rasmussen's statement was paraphrasing another person's words, but was in affirmation of those words. 